www.jmscr.igmpublication.org

Impact Factor 5.244

Index Copernicus Value: 83.27

ISSN (e)-2347-176x ISSN (p) 2455-0450

crossref DOI: _https://dx.doi.org/10.18535/jmscr/v4i10.49

Journal Of Medical Science And Clinical Research

IGM Publication

An official Publication of IGM Publication

\title{
A Cross-Sectional Study on Musculoskeletal Disorders among Textile Mill Workers in Ahmedabad City
}

\author{
Authors \\ Dr Sandeep Kumar Chauhan, Dr Arohi Chauhan, Dr Aparajita Shukla \\ Department of Community Medicine, Smt. NHL MMC, Ahmedabad \\ Corresponding Author \\ Dr. Sandeep Kumar Chauhan \\ 5B/9, Pratap enclave, Colvin Road, Civil lines, Allahabad - 211001 \\ Email:arohi_285@yahoo.co.in, M:8238006260
}

\begin{abstract}
Musculoskeletal disorders (MSDs) are the most common work-related health problem, with almost one in four workers reporting backache and one in five complaining of muscular pains. Manual handling, lifting, holding, putting down, pushing, pulling, carrying or movement of a load, is the largest cause of injury in the textiles sector. Hence, A cross-sectional study with the aim of assessing prevalence of MSDs was conducted among Textile mill workers. Methodology: The study was carried out in five textile mills located in and around Ahmedabad city during August 2011 to August 2012. Result: Prevalence of MSDs was 17.9\%. Out of which, 15 (1.7\%) had MSDs related to upper limb, 25(2.8\%) had MSDs related to lower limb, 64(7.2\%) had back pain while 55(6.2\%) had bodyache. Occurrence of MSDs was related to pre-employment training status and Body Mass Index whereas MSDs occurrence was not related to age of the workers. Conclusion: MSDs are widely prevalent among textile mill workers and it has an important relationship with pre-employment training and BMI. So, more emphasis is needed to train the workers before they start their job to reduce MSDs in order to have a healthy workforce ultimately contributing to high productivity and gains.

Keywords: Musculoskeletal disorders, textile mill workers, training.
\end{abstract}

\section{Introduction}

In India, 20 million workers are involved in the manufacturing of textiles. Worldwide, India is the second largest producer of textile goods, which account for $20 \%$ of the national industrial output. Twenty million workers are employed in 1175 cotton mills across the country, representing a major occupational group. ${ }^{1}$

Industrialization is necessary for prosperity and at times for the survival of a Nation. The production is the real wealth of a Nation. Only industrialization is not enough, real benefit is brought by continuous top performance of the worker which is only possible by their good health. Industrial workers constitute only a segment of general population and the factors that influence the health of the population also apply equally to industrial workers i.e. water supply, sewage and waste disposal, nutrition and education, and the conditions prevailing in their place of work. ${ }^{2}$

Occupational environment is the sum of external condition and influences which prevail at the place of work and which have a bearing on the 
health of the working population. The industrial workers today are placed in a highly complicated environment which is getting more complicated as man is becoming more ingenious. ${ }^{2}$

The textiles sector contains many hazards and risks to workers, ranging from exposure to noise and dangerous substances, to manual handling and working with dangerous machinery. Each processing stage, from the production of materials to the manufacturing, finishing, colouring and packaging poses risks for workers, and some of these are particularly dangerous for women's health. ${ }^{3}$

Musculoskeletal disorders (MSDs) are the most common work-related health problem, with almost one in four workers reporting backache and one in five complaining of muscular pains. Manual handling, lifting, holding, putting down, pushing, pulling, carrying or movement of a load, is the largest cause of injury in the textiles sector. ${ }^{3}$

Hence, a cross-sectional study was conducted with the aim to assess the prevalence of MSDs among textile mill workers.

\section{Methodology}

The study was carried out in five textile mills located in and around Ahmedabad city. The study was carried out during August 2011 to August 2012. A Pre-designed, pre-tested questionnaire was used to record information which included socio-demographic variables, detailed history of work exposure and Work related injuries \& musculoskeletal disorders.

All the workers (889) of the five textile industries were studied after obtaining their written informed consent as well as due permission from the Department of Community Medicine, Ethics committee of the institute \& concerned authority of the textile mills were also taken.

\section{Result}

Mean age of the workers was $43.5+11.0$ years, ranged from 16 to 74 years. At the time of study, total $529(59.5 \%)$ workers had addiction in form of chewing, smoking or drinking. Median duration of any addiction was 10 years. Majority 795 $(89.4 \%)$ of the workers had 8 hours duty period while $15(1.7 \%)$ had 10 and 79 (8.9\%) had 12 hours. Cumulative cotton dust exposure ranged from 6 months to 57 years with median duration of 20 years. Workers with cotton dust exposure for more than 20 years were 420 (47.2\%).

Prevalence of MSDs was $17.9 \%$. Out of which, 15 (1.7\%) had MSDs related to upper limb, 25(2.8\%) had MSDs related to lower limb, 64(7.2\%) had back pain while $55(6.2 \%$ ) had bodyache. (Table 1 ) History of musculoskeletal disorders didn't show significant association with age. Musculoskeletal disorders were equally present in all the agegroups. (Table 2)

Out of the total 889 workers, only 301 (40.1\%) of the workers had pre-placement training for their job. Other trainings were taken intermittently by some which included use of personal protective devices 166 (22.1\%), fire safety 217 (28.9\%), first aid $174(19.6 \%)$ etc. The proportion of musculoskeletal disorders was 2.6 times more in un-trained workers on how to operate machine safely as compared to trained workers. (Table 3)

According to body mass index examination, 22\% workers were underweight, $13 \%$ overweight while rest were normal. Over-nourished/over-weight workers had 1.3 times higher history of musculoskeletal disorders as compared to normal. (Table 4)

Table 1: Prevalence of Musculoskeletal disorders ( $\mathrm{n}=889)$

\begin{tabular}{|c|c|c|c|c|}
\hline No. & \multicolumn{2}{|c|}{ Musculoskeletal problems } & Previous job $(n=300)$ & Present job $(n=889)$ \\
\hline \multirow[t]{2}{*}{1} & \multirow[t]{2}{*}{ Upper limb } & Shoulder joint & 0 & $10(1.1 \%)$ \\
\hline & & Wrist joint & 0 & $5(0.6 \%)$ \\
\hline 2 & Lower limb & Osteoarthritis & $1(0.3 \%)$ & $25(2.8 \%)$ \\
\hline 3 & \multicolumn{2}{|c|}{ Back pain } & $3(1.0 \%)$ & $64(7.2 \%)$ \\
\hline 4 & \multicolumn{2}{|c|}{ Body ache } & 0 & $55(6.2 \%)$ \\
\hline \multicolumn{3}{|c|}{ Total } & $4(1.3 \%)$ & $159(17.9 \%)$ \\
\hline
\end{tabular}


Table 2: Comparison between presence of musculoskeletal disorders and age

\begin{tabular}{|l|c|c|c|c|l|}
\hline \multirow{2}{*}{$\begin{array}{l}\text { History of musculoskeletal } \\
\text { disorders }\end{array}$} & \multicolumn{3}{|c|}{ Age ( in years) } & Total & \multirow{2}{*}{ Chi-square } \\
\cline { 2 - 4 } & $<40$ & $40-49$ & $>50$ & & \\
\hline Yes & 48 & 46 & 61 & 155 & 1.708 \\
& $(5.4 \%)$ & $(5.2 \%)$ & $(6.9 \%)$ & $(17.4 \%)$ & $(\mathrm{df}-2$, \\
No & 237 & 247 & 250 & 734 & $\mathrm{P}=0.426)$ \\
& $(26.7 \%)$ & $(27.8 \%)$ & $(28.1 \%)$ & $(82.6 \%)$ & \\
\hline Total & 285 & 293 & 311 & 889 & \\
& $(32.1 \%)$ & $(33.0 \%)$ & $(35.0 \%)$ & & \\
\hline
\end{tabular}

Table 3: Association between training on how to operate machine safely and history of musculoskeletal disorders $(\mathrm{n}=751)$

\begin{tabular}{|l|c|c|c|c|c|}
\hline Training on how to & \multicolumn{2}{|c|}{ Presence of musculoskeletal disorders } & Total & Chi-square & Odd's ratio \\
\cline { 2 - 4 } operate machine safely & Yes & No & & & \\
\hline Taken & 32 & 269 & 301 & & \\
& $(4.3 \%)$ & $(35.8 \%)$ & $(40.1 \%)$ & 20.667 & 2.622 \\
\cline { 1 - 3 } Not taken & 107 & 343 & 450 & $(\mathrm{df}-1$, & (95\% CI: \\
& $(14.2 \%)$ & $(45.7 \%)$ & $(59.9 \%)$ & P=0.0001) & 1.713 to \\
\cline { 1 - 4 } Total & 139 & 612 & 751 & & 4.015 \\
& $(18.5 \%)$ & $(81.5 \%)$ & & \\
\hline
\end{tabular}

Table 4: Comparison between presence of MSDs and Body Mass Index (BMI)

\begin{tabular}{|c|c|c|c|c|}
\hline \multirow[t]{2}{*}{ Body Mass Index ${ }^{30}$} & \multicolumn{2}{|c|}{ Presence of MSDs } & \multirow[t]{2}{*}{ ODD's ratio } & \multirow[t]{2}{*}{ Chi-square } \\
\hline & Yes & No & & \\
\hline $\begin{array}{l}\text { Under-nourished } \\
(\mathrm{n}=200)\end{array}$ & $\begin{array}{c}30 \\
(3.4 \%)\end{array}$ & $\begin{array}{c}170 \\
(19.1 \%)\end{array}$ & $\begin{array}{c}0.8369 \\
(95 \% \text { CI: } 0.5359 \text { to } 1.307)\end{array}$ & \multirow{3}{*}{$\begin{array}{c}2.132 \\
(\mathrm{df}-2 \\
\mathrm{p}=0.344)\end{array}$} \\
\hline $\begin{array}{l}\text { Normal } \\
(\mathrm{n}=557)\end{array}$ & $\begin{array}{c}97 \\
(10.9 \%)\end{array}$ & $\begin{array}{c}460 \\
(51.7 \%)\end{array}$ & Reference category & \\
\hline $\begin{array}{l}\text { Over-nourished } \\
(\mathrm{n}=132)\end{array}$ & $\begin{array}{c}28 \\
(3.1 \%) \\
\end{array}$ & $\begin{array}{c}104 \\
(11.7 \%) \\
\end{array}$ & $\begin{array}{c}1.277 \\
\text { (95\% CI: } 0.7969 \text { to } 2.046)\end{array}$ & \\
\hline
\end{tabular}

\section{Discussion}

Disorders of the musculoskeletal system are the single largest group of work-related illness in the developing and developed world. Sedentary working style with wrong posture for long time can be important risk factor for the development of this disorder. ${ }^{4}$

Prevalence of MSDs in the present study is $17.9 \%$. Guo et $\mathrm{al}^{5}$ in Taiwan observed prevalence of MSDs as $35.2 \%$. In another study conducted by Fantahun et $\mathrm{al}^{6}$, prevalence of MSD was $6.3 \%$. Jahan et $\mathrm{al}^{4}$ in Bangladesh observed prevalence of MSD as $60 \%$.

The origin of MSDs is complex and multifactorial. Amongst various risk factors, such as heavy lifting and high job demands, it has been suggested that high body mass index (BMI) (overweight and obesity) might be an independent risk factor for MSDs. For symptoms of neck/ shoulder, upper and lower limbs, evidence was also found that high BMI is an independent risk factor for the development of (symptoms of) MSDs. $^{7}$

Current study observed a 1.3 times higher risk of development of MSDs among obese/overweight compared to normal weight workers. Jahan et $\mathrm{al}^{4}$ also observed increased risk of MSDs among overnourished workers $(\mathrm{p}<0.07)$

Training enhances skills of workers hence reducing the chances of occurrence of MSDs. In the present study a significant association was observed between occurrence of MSDs and untrained workers. Pre-employment training should be a compulsory exercise in every textile mill as unskilled workers represent a major workforce in industries in developing countries.

\section{Conclusion}

Hence, from the above study it can be concluded that MSDs are widely prevalent among textile mill workers and it has an important relationship with pre-employment training and BMI. So, more 
emphasis is needed to train the workers before they start their job to reduce MSDs in order to have a healthy workforce ultimately contributing to high productivity and gains.

\section{References}

1. Mishra AK, Rotti SB, Sahai A, Mohan M, Narayan KA. Byssinosis among male textile workers in Pondicherry: A casecontrol study. The National Medical Journal of India Mar-Apr 2003;16(2)

2. Jaiswal A. Health Status Of Textile Industrial Workers of Utter Pradesh, India. EAA Summer School eBook 1: 217223. http://eaa.elte.hu/Jaiswal.pdf (Last accessed on $3^{\text {rd }}$ Jan 2013)

3. Occupational safety and health in the textiles sector. European Agency for Safety and Health at Work https://osha.europa.eu/en/publications/e-facts/efact30 (Last accessed on $3^{\text {rd }}$ Jan 2013)

4. Nusrat Jahan, Manisha Das, Rajib Mondal, Sunanda Paul, Trissa Saha, Rahima Akhtar, Abdul Mahid Khan5, Palash Chandra Banik. Prevalence of Musculoskeletal Disorders among the Bangladeshi Garments Workers.SMU Medical Journal, , January, 2015;2(1):102-13.

5. How-Ran Guo, Ya-Ching Chang, Wen-Yu Yeh, Chun-wan Chen and Yueliang L Guo. Prevalence of Musculoskeletal Disorder among workers in Taiwan: A Nationwide Study. J Occup Health 2004; 46:26-36

6. Mesganaw Fantahun, Yekoye Abebe. Selfreported disease conditions among workers ofthe textile mill in Bahir Dar, Northwest Ethiopia. Ethiopian Journal of Health Development,1999;13(2):151-56.

7. Laura Viester, Evert ALM Verhagen, Karen M Oude Hengel, Lando LJ Koppes, Allard $\mathrm{J}$ van der Beek and Paulien M Bongers. BMC Musculoskeletal Disorders 2013;14:238-46. 